\title{
UN JARDÍN PARA LOS INDIOS, EN BARTOLOMÉ DE LAS CASAS
}

\author{
A GARDEN FOR THE INDIANS, IN BARTOLOMÉ DE LAS CASAS
}

\author{
Vanina M. Teglia*
}

\begin{abstract}
La Historia de las Indias y la Apologética historia sumaria de fray Bartolomé de las Casas escasean de referencias a la naturaleza del Nuevo Mundo, específicamente del Caribe. Las pocas alusiones a la flora, fauna y geografía indianas son tópicos del jardín fértil y placentero tomadas de Cristóbal Colón y luego reelaboradas. Lo principal para el fraile resultaba ser la relación de los nativos con su espacio natural. Por esto se sirvió del modelo de la Arcadia para representar la geografía anterior a la conquista, pues en ella lo principal es la condición de convivencia armónica entre el espacio y sus habitantes, que se contentan felizmente con poco. En cambio, para dar cuenta del espacio luego de la colonización española, Las Casas apeló a la tradición de Cucaña, en la que sus habitantes viven en el exceso y su naturaleza resulta un desierto despojado. La clave que autoriza el vínculo entre el espacio y los hábitos de sus naturales es el concepto filosófico del determinismo ambiental. Por último, concluimos que la mención constante a la Arcadia indígena perdida constituye un elemento de persuasión esperanzadora que persigue retóricamente la restauración del espacio natural perdido.
\end{abstract}

Palabras claves: Siglo XVI, Nuevo Mundo, naturaleza, determinismo ambiental, Las Casas.

The Historia de las Indias and Apologética historia sumaria by fray Bartolomé de las Casas makes a little number of references to the New World nature, specifically to Caribbean nature. The few allusions to the Indian flora, fauna and geography are all rewritings of the fertile and pleasant garden taken from Christopher Columbus' texts. The friar's main interest turned out to be the relation between natives and their natural environment. For this reason, he made use of the descriptive model of Arcadia to represent the Indian geography before the Conquest, because it emphasizes, among other elements, the harmonic coexistence between space and its inhabitants, who need so little to live happily. On the contrary, to characterize the Indian space after the Spanish colonization, Las Casas invoked the tradition of Cucaña, where its inhabitants live with excess and the nature ends up being a bare desert. In order to explain the links between space and the habits of the natives, he turns to the authoritative theory of determinism. Finally, I reach the conclusion that the constant mention to the lost Indian Arcadia constitutes a pervasive and hopeful element that rhetorically follows the restoration of the lost natural space.

Key words: 16th century, New World, nature, environmental determinism, Las Casas.

Los españoles son obligados a restituir a los indios todas las tierras que les han tomado; $y$ no las restituyendo, no se salvarán.

Bartolomé de las Casas, "Respuesta sobre los sucesos de la conquista del Perú" (1822:309).

\section{Introducción}

Este artículo se despliega a partir de la pregunta acerca de por qué, en la obra histórica de Bartolomé de las Casas (la Historia de las Indias y la Apologética historia sumaria), se encuentran muy pocas alusiones al espacio americano, es decir, a su naturaleza, paisaje o a la flora, fauna y geografía americanas en comparación con otros cronistas y también en comparación con la inmensa cantidad de páginas que el fraile dedica a los nativos amerindios. $\mathrm{La}$
Apologética historia sumaria, por ejemplo, busca seguir el modelo de escritura y los intereses de las historias naturales ${ }^{1}$ en donde parecería que la descripción de las cualidades de la tierra deberían tener la misma importancia que la condición de su gente. Sin embargo, el fraile no se detiene demasiado en la descripción del paisaje caribeño -que es el que efectivamente conocía con profundidad-, aunque sí acerca del estudio de sus habitantes naturales, que era la cuestión de la que quería dar cuenta con urgencia. Abandona prontamente estos intereses y coloca toda la atención en la naturaleza del indio, por lo que los capítulos de esta obra, como tantos otros textos pertenecientes al extenso corpus de las Crónicas de Indias escritas en español, adquieren un carácter protoetnográfico. Por otra parte, en la Historia de las Indias, que no intenta seguir el modelo más puro de la historia natural, sucede

\footnotetext{
* Universidad de Buenos Aires, CONICET. Buenos Aires, Argentina. Correo electrónico: vaninateglia@ filo.uba.ar
} 
lo mismo: la representación de las condiciones y de los hechos de los nativos prevalece por sobre la descripción de la geografía y la naturaleza indianas. En muchos casos, los párrafos destinados a estas cuestiones del espacio son inserciones de relatos de otros autores, mayormente tomadas de los diarios de Cristóbal Colón, luego reelaboradas en parte por el fraile. Al respecto, sostengo que, mientras las representaciones colombinas acerca del indio fueron acentuadamente desmenuzadas y revisadas en general, sus afirmaciones respecto de la naturaleza de las Indias occidentales fueron muy tímidamente corregidas por Las Casas y también por otros cronistas.

Sostengo en este artículo que, para dar cuenta del espacio americano, Las Casas en su Historia y en la Apologética ofrece visiones de la naturaleza estrechamente ligadas a los individuos y a sus prácticas y modos de vida. Es decir, las representaciones de la naturaleza son escasas en la obra del fraile y son ubicadas en un segundo plano porque lo que interesa es la relación que los individuos tienen con ella. Para alcanzar este propósito -como se verá-, el autor, cuando representa el momento previo a la llegada de los españoles al Nuevo Mundo, apela al modelo de la Arcadia de convivencia armónica entre el paisaje prístino y sus habitantes de hábitos moderados. Ahora bien, propongo que esta oscilación entre modelos y tópicos se halla autorizada por la convicción filosófica del determinismo ambiental y climático, en la que la representación del espacio no puede ser aislada de la representación de sus habitantes. Para este pensamiento, la condición "razonable" del habitante determina la armonía y prodigalidad del paisaje indiano, así como este influye sobre la "buena disposición" del cuerpo y la mente de los amerindios. En cambio, para ofrecer una visión del paisaje que resulta de las acciones de los españoles, el fraile se sirve de la tradición de Cucaña. Demostraremos que, en la Historia de las Indias, la visión utópica es también una estrategia de persuasión que apela a un pensamiento esperanzador que busca transformar la destrucción en restauración del paisaje "feliz".

\section{Utopías de las Indias}

Para comenzar el análisis, retomemos las imágenes de Cristóbal Colón, quien se sirve de ciertos elementos fijados por la literatura clásica para definir la naturaleza del Nuevo Mundo: la suavidad del aire, la fertilidad de la tierra, la abundancia del agua y el exotismo de la fauna, entre otros. A diferencia de las representaciones ambiguas, contradictorias y caleidoscópicas acerca del nativo americano (Solodkow 2014), las visiones colombinas respecto de la naturaleza -particularmente, las del primer diario- son fijas, casi como si se hubieran bañado en las aguas de la fuente de la eterna juventud; satisfacen en su justa medida el placer estético y la esperanza de la alimentación y de la riqueza por medio de su visión. Conforman lo que Curtius llamó la descripción literaria de la belleza natural, elaborada y fijada tradicionalmente por la poesía griega, luego muy difundida por Virgilio y Ovidio; evocada en la persistencia del motivo del locus amoenus en la poesía pastoril, en la novela helenística, en los poetas cristianos, en la épica y en la literatura de caballerías. Ernst Bloch considera que estos motivos concatenados pertenecen a una superestructura (Bloch 1983:328) -ideas, imágenes, representaciones- del "deseo del Paraíso en la tierra" que fue conformándose para describir lugares lejanos e identificados con dicho deseo, que debía existir en algún lugar. Esta superestructura deseada puede ser identificada con el nombre de "paraje ameno", pero ha recibido varias denominaciones y caracterizaciones a lo largo de los siglos. Edad de Oro para los antiguos -si está referida a un pasado ideal del hombre-, Arcadia, visiones del Edén o del Paraíso, Jardín de las Delicias, Islas Afortunadas, Campos Elíseos e isla de Thule son algunos de los nombres con que ha sido designada. Se trata de una amalgama de mitos y tradiciones grecorromanas y judeocristianas (Manuel y Manuel 1984), una fusión de motivos e imágenes poéticas (Curtius 1955) o un desplazamiento de unas concepciones por otras que son revividas en épocas posteriores. De esta manera, los modos de representación del paisaje de la época no se ajustan a un criterio de "fidelidad" u "objetividad". Las descripciones medievales de la naturaleza, por ejemplo, no aspiraban a la mímesis realista sino que apuntaban a la belleza o a la persuasión moral. Las ideas y mitos de aparición insistente perduran en el imaginario y en el lenguaje a pesar de la revaloración del testigo de vista y paralelamente a ella.

Las descripciones lascasianas, por ejemplo, o las colombinas que Las Casas selecciona para componer su Historia, por un lado reproducen imágenes o tópicos aparecidos en otros textos, 
por el otro, crean la ilusión de que lo representado puede ser verificable y confrontable con lo real. El primer modo de exposición trabaja "entre textos"; el segundo responde al modo de registro propio del testigo o del viajero, que también corresponde a una retórica cuya finalidad es convencer al lector del carácter factual de lo descrito. Ambas formas confluyen en la representación de la geografía americana. Por ejemplo, observemos el siguiente fragmento:

[el Almirante] vido el valle grande, donde estaban las poblaciones, de que quedó admirado, diciendo que no había visto en su vida cosa más hermosa, por lo cual le puso al valle, del Paraíso, y al río, Guadalquivir, porque parecía al Guadalquivir cuando va por Córdoba (Casas L I, c 54 [MC I:261]).

Se fusionan aquí los tópicos edénicos para representar la naturaleza de las tierras desconocidas. Hay un asombro ante la visión de la maravilla hiperbólica: "no había visto en su vida cosa más hermosa", que el Almirante reinscribe en la tradición de lo más hermoso y desconocido: el Paraíso, que "existe" descrito en textos del pasado. Luego, Las Casas introduce la analogía que compara el paso del río por el valle antillano con el del Guadalquivir por la ciudad española de Córdoba. La representación se provee de las referencias constantes a lo visto -que constituyen al Almirante como testigo de la maravilla-, de la analogía con el elemento conocido por los lectores y, por último, de la alusión a lo inefable por medio de una referencia a los textos bíblicos. En esto, seguimos las definiciones de lo descriptivo de Philippe Hamón, para quien el placer general de la descripción se encontraría más en el reencuentro y en la recordación que en el descubrir cosas nuevas. De este modo, el hacer presente lo descrito a los lectores consiste en una apelación a la memoria y un uso de la hipotiposis, especie de hipérbole, que es, según Hamón (1991:83), propia de la descripción. Estrictamente, esta última figura retórica consiste en "poner ante los ojos", en "hacer ver" el objeto resaltando sus detalles característicos y cautivando la atención del oyente. En el fragmento de Colón retomado por Las Casas se apela al testimonio de vista ("vido el valle grande"), a la memoria (el Guadalquivir, Córdoba, el Paraíso descrito en los textos) y a la hipotiposis ("cosa más hermosa"). De acuerdo con las retóricas del Renacimiento, el placer del lector estaba en "recordar" y en "encontrar de nuevo" la geografía y la hipérbole descriptiva conocidas.

No se trata de la naturaleza inarmónica, amenazante o salvaje sino del oasis controlado, maravilloso pero esperado. El "jardín americano" es un espacio accesible -todos pueden constatar su felicidad una vez allí-, pero también es cerrado y se encuentra aislado por la extensión y profundidad del mar Océano -el non plus ultra- que media entre el espacio conocido y el desconocido. Para el pensamiento utópico, esta misma inaccesibilidad del paisaje -aislado también del transcurso del tiempo- asegura su perfección (Levin 1972:58), lo mantiene invariable en el imaginario que lo representa "desde lejos" o "mucho tiempo después". Fernando Aliata y Adriana Silvestri (2001) han señalado registros de los primeros jardines cerrados de esta tradición, tan cerrados como una ciudad, lo que implicaba necesariamente un límite. Los autores han encontrado referencias a ellos en Egipto: consistían en espacios cercados por muros que datan de 1400 a.C., con árboles, campos floridos y fuentes: un oasis de vida en las secas extensiones. En la representación del espacio indiano, el océano Atlántico constituye el límite, geográfico en este caso, que lo vuelve hermético frente a las variaciones y contingencias. El espacio invariable consiste en una excepción en medio del transcurso cambiante del tiempo. Por esto, usualmente las visiones edénicas suelen ser islas imperturbables que no siguen las pautas del mundo.

De modo similar y sirviéndose de estas connotaciones orientales, describe Bartolomé de las Casas los jardines en la ciudad mexica de Cempoal: "en cada casa su huerta, con su agua de pie, que toda ella era un vergel y un Paraíso terrenal" (L III, c 122 [MC III:251]). "Vergel" es el término que elige el fraile, su sentido unifica las posibilidades semánticas del jardín fértil: huerto, parque, prado, oasis, edén. El término tenía, en la época, la connotación de "jardín" en que "se crían de ordinario flores y plantas odoríferas, que difieren de los huertos porque estos tienen árboles y frutales, el verjel es de sola recreación, para alegrar la vista" [Covarrubias 1611]. De este modo, no hay tierra que pueda ser explotada, es solo para el placer. Resuenan, de esta manera, las descripciones del Paraíso como jardín celestial presentes en el Génesis bíblico. Ubicado al oriente de Jerusalén, el Edén, por obra del Dios cristiano, desborda de fertilidad: árboles, ríos y 
frutos sabrosos. Los mismos elementos -árboles hermosos, de frutos sabrosos, un río que cruza el jardín-definen al huerto medieval y al jardín secreto renacentista. La tradición de la poesía bucólica o pastoril también utiliza estas imágenes.

De este modo, Las Casas incluye muchas descripciones provenientes del relato de Colón; sin embargo, al comentarlas, simplifica las referidas al paisaje. La operación del fraile en relación específicamente con las descripciones geográficas de las Indias consiste en tomar como reales y comprobadas las palabras de Colón y luego, en sus comentarios, reducirlas o no enfatizar todas las cualidades detalladas originalmente en el Diario. El paisaje sigue siendo ideal o idealizado. Sin embargo, el énfasis mayor está puesto en la connaturalidad entre contexto geográfico y sus habitantes. Por ejemplo, el siguiente comentario de Las Casas a una extensa cita de Colón sobre la naturaleza propone:

Debe aquí el lector considerar (...) qué tierras estas más felices que nos puso la divina Providencia en las manos para pagarnos aun en esta vida, sin lo que habíamos de esperar en la otra, los trabajos y cuidados que en atraerlas a Cristo tuviéramos (Casas, L I, c 53 [MC I:260]).

"Felices" tiene el significado de "dichosas" y "venturosas" (Covarrubias 1611). Pero ¿a quiénes o a qué alude Las Casas precisamente con "atraerlas a Cristo"? Evidentemente, el referente en el con-texto es la palabra "tierras" y por esto la expresión es una hipálague o una sinestesia particular, en donde el complemento se refiere a una palabra distinta de aquella a la cual debería referirse lógicamente. Ahora bien, "tierras" ("felices") tiene además un significado ambiguo, pues no está claro si se refiere al paisaje o a su gente. El término refiere tanto a los nativos felices como al paisaje placentero, ideal, feliz y que hace felices a sus habitantes, y esto es a causa de que, en Las Casas, las condiciones de ambos se confunden o están consustanciadas. Hay ambiguiedad en la escritura del fraile, ya que este aprovecha la descripción geográfica de Colón para también desplazar el sentido "feliz" sobre los nativos.

La tierra como proveedora que alimenta, que da vida y satisface las necesidades primordiales de sus habitantes es un lugar común de larga tradición literaria. Está en Hesíodo y en Ovidio, primeros retratadores de la Edad de Oro en el pensamiento occidental. Ellos fundaron esta tradición según la cual la gran productividad de la tierra basta para que los hombres dediquen poco tiempo al trabajo. ${ }^{2}$ En "Las edades del hombre" de las Metamorfosis, se utiliza una hipérbole para definir la relación directa entre fertilidad de la tierra y ocio de los hombres. Cualquier trabajo humano, además de ser una agresión a la naturaleza, es totalmente innecesario. Por la abundancia de recursos naturales, o sea, sin necesidad del mucho trabajo para la satisfacción de las necesidades, los pueblos pueden vivir pacíficamente y así las tierras son "felices". Más aún, la teoría del clima o "del medio", desde Hipócrates, parecía poder explicar las diferencias entre las razas a partir de ciertos fenómenos observables como la situación geográfica, el clima y el suelo. Estas cuestiones tenían sus fundamentos en una noción simple de afirmación de la unidad del mundo natural (Pagden, 1988:191) que luego se resumirá en una idea estoico-renacentista de correspondencia mágica entre el mundo humano y la naturaleza (Frankl 1963:460). Bartolomé de las Casas cita varias autoridades al respecto en su Apologética: Aristóteles, Hipócrates, Avicena, Averroes, Ptolomeo, Galeno, Alberto Magno, Santo Tomás, entre otros. Un libro citado por Las Casas: De Regimini (atribuido a Santo Tomás, pero que es obra de Tolomeo de Luca) explica que las diferencias entre los hombres deben buscarse en las influencias del clima y de los astros.

Ahora bien, desde otro lugar, esta Teoría del Medio recurrentemente se utilizaba para justificar prejuicios y estereotipos positivos sobre el grupo de pertenencia y negativos sobre los Otros. ${ }^{3}$ Estos eran suficientes para explicar la esclavitud natural, a diferencia de la esclavitud legal. En esta línea de pensamiento, el ambiente americano -ya sea de regiones frías o cálidas, altas o bajas- fue en ocasiones visto como influencia nefasta en los seres: los disminuía, afeaba o debilitaba. Así, a fines del siglo XVI, el cosmógrafo oficial del Consejo de Indias, Juan López de Velasco, escribía a propósito de los indios: "Son de ordinario de menor cuerpo y más débiles y flacos por la relajación del calor y vicio de la tierra". ${ }^{4}$ Antonello Gerbi también cita al dominico Juan de la Puente quien, en 1612 sostenía que los naturales en las Indias caían fácilmente en la idolatría, porque el cielo de América "influye inconstancia, lascivia y mentira" (Gerbi 1960:69). Mucho antes, también habían aparecido comentarios relativos al determinismo ambiental en 
relación con los nativos americanos. El mismo Las Casas recoge, por ejemplo, las Siete proposiciones formuladas en 1512 por fray Bernardo de Mesa a solicitud de Fernando el católico y presentadas como informe para la elaboración de las Leyes de Burgos. Aunque defendiendo en general la libertad de los indios, la segunda proposición en cambio asegura la necesidad de la esclavitud cuando esta fuera natural. Tal sería el caso de los siervos por la naturaleza de la tierra: "hay algunas tierras a las cuales el aspecto del cielo hace siervas, [y no podrían ser bien regidas] si en ellas no hubiera alguna manera de servidumbre" (cita de Mesa en Las Casas: L III, c 9 [MC II:459]).

Las Casas corregirá estas interpretaciones previendo sus usos futuros, e invirtiendo la mentalidad colonialista reforzada por este sistema explicativo y justificativo. Se apropiará, en el mismo terreno teórico, de los conceptos y teorías de base para llegar a conclusiones totalmente diferentes. Por ejemplo: "[aquesta gente] de su natural eran delicatísimos como hijos de príncipes por razón de las regiones $\mathrm{y}$ aspectos de los cielos y suavidad o amenidad de las tierras y por otras causas naturales (Casas, L III, c 144 [MC III:327])". Si el clima, la geografía y el suelo determinan la calidad de los habitantes, para combatir el discurso colonialista solamente habría que describir las "felicidades" de las tierras indígenas y su propicia "habitabilidad". Así, el fraile acepta las premisas de la teoría del medio, porque fundamentan su tesis. La Apologética, pero también la Historia de las Indias, combinan la descripción con la explicación causal y resul$\tan$ en representaciones de una naturaleza fértil, armónica, paradisíaca y bella. De esta manera, la tierra de las Indias es rica y fértil, en realidad, porque sus habitantes sencillos son moderados. El espacio no puede ser definido aislado de su sujeto. Así, en Las Casas:

Y porque los indios comúnmente no trabajaban ni querían tener más comida de la que habían para sí e para sus casas menester (como la tierra para sus mantenimientos fuese fertilísima, que con poco trabajo dondequiera tenían cuanto al pan cumplido y cuanto a la carne cabe casa, como en corral habían las hutías o conejos y del pescado llenos los ríos) (...), porque no solo se contentaban ni se contentan con tener lo necesario, pero mucho sobrado
(...) (Casas, L I, c 100 [MC I:398]) [lo

destacado es nuestro].

Hacia el final de este párrafo, hay una refutación: se niega un enunciado -"no solo se contentaban ni se contentan con tener lo necesario"-y luego se ofrece una rectificación -"pero mucho sobrado". Se refuta el razonamiento de un adversario (el pensamiento de los otros cronistas), pues se disocia el "contentarse con poco" de una hipotética falta de ambición que otros cronistas, como Fernández de Oviedo, solían asociar a los amerindios. En cambio, propone Las Casas, en tanto los hombres se contengan y no se abusen de la naturaleza, la tierra puede ser fértil y abundante (ellos tienen "de sobra").

La representación de esta sociedad ideal parte del modelo de la Arcadia. Comúnmente suele vinculársela con el mito de la Edad de Oro y con los paisajes de la literatura bucólica. En Arcadia, los hombres son moderados y trabajan, pero poco. Está implícito que le dedican gran parte del tiempo al ocio. "En Arcadia, a diferencia de Cucaña, los hombres trabajan, pero su carga es alegre y ligera (...) viven en la comodidad y la abundancia, no en el exceso". (Davis 1985:32). Es un estado de reposo y contentamiento, tal como lo expresa Las Casas de los amerindios. Por momentos, este fraile pareciera decir que la tierra de las Indias y su producción solamente son suficientes para los indios y que, si otros la explotasen, se convertiría en terreno yermo. El espacio utópico, así, no es lugar para los españoles que sostienen tales conductas reprobables. Las Indias no son fértiles por sí mismas sino que son fruto del comportamiento moderado que con ella tienen los hombres que la habitan. "Moderado", por otra parte, va a ser interpretado de manera muy diferente por el cronista Fernández de Oviedo, enemigo político e ideológico constante de Las Casas. Para el Cronista Oficial, el poco trabajar y el ocio de los indios son "vicios" y signos de su poca constancia: "esta gente es ociosa e viciosa, e de poco trabajo" (Oviedo; L 3, c 6 [PT I: 67]). Por un lado, coincide con Las Casas en que la tierra fértil no es digna de españoles "viles" que no miden sus acciones explotadoras, pero, por otro lado, para Oviedo, la condición fértil de la naturaleza abre las puertas a la codicia y a los vicios de todos los hombres viles: es decir, de todos los indios y de ciertos españoles. Al contrario, en Las Casas, la condición moderada de algunos hombres (todos los indios, la mayor parte de los frailes y algunos 
pocos españoles seglares) permite el crecimiento y la fertilidad deseada en la naturaleza. En Oviedo, se piensa a la naturaleza como contenedora de una amenaza latente: su fertilidad es exceso que "tienta" a los hombres. El anhelo de este cronista es, justamente, controlar el paisaje y sofocar los caóticos y lascivos deseos de los hombres "de poca razón". En cambio, el deseo de Las Casas es que la naturaleza indiana y sus naturales -viviendo en una especie de Edad de Oro- permanezcan intactos, seguros y no se vean afectados por la Conquista.

Consideramos que, respecto de estos temas, Las Casas se halla particularmente inspirado por algunos conceptos de Santo Tomás de Aquino como el de la Edad de la ley natural, época anterior al diluvio, en parte idéntica a la Edad de Oro clásica. Según Anthony Pagden (1988:82), la idea de que los indios vivían su propia "edad de la ley natural" estaba muy extendida. Se halla asociada a lo razonable, porque la ley natural es la que rige los preceptos básicos (prima praecepta) del hombre "verdadero". Esta armonía se proyecta sobre varias instancias "naturales". Por ejemplo, en Apologética:

[en las islas de los Lucayos] ¿Quién contará los frutales y las naturalezas de ellos, y la suavidad y sanidad juntamente de sus frutas y la multitud numerosa, así domésticos como silvestres? Todos estos árboles son amigos, según sentencia de los médicos, de la complisión humana (Casas, cap. XXI [1909:51]).

Se refiere a la abundancia con las figuras de la acumulación, la hipérbole y el adjetivo pleonástico: "multitud numerosa". Se prueba que el habitante natural está cómodo con la naturaleza porque ella determina su salud. Esto implica que el hombre también está en paz con su propia naturaleza, con su cuerpo. Así, la tierra es fértil porque estos humanos -"verdaderos", razonables y moderados- no la alteran. Estos, por su parte, poseen una complexión armónica, porque los frutos de los árboles, muy numerosos, son sanos, aunque sean "silvestres" o salvajes. La Naturaleza es buena, porque los hombres no trastornan su ritmo "natural" y, viceversa, son sanos, moderados, razonables y bondadosos, porque la Naturaleza les provee de salud y equilibrio.

Sin embargo, este estado primitivo de seres viviendo en un "jardín" no implica, en el fraile sevillano, un rechazo a concebir a las Indias con características propias de una sociedad organizada. No es, en este sentido, la pastoral que se opone al estado de sociedad. ${ }^{5}$ En cambio, es la vida civilizada, moderada e indiferente a los vicios. Es una Arcadia indígena, sin la corrupción que le imprimen los "vicios" y plena de la abundancia que brinda la fertilidad y la sociedad civilizada pero sencilla. El hecho de argumentar que los indios tienen su propia organización en ciudades le permite, al fraile, rebatir el postulado que venían sosteniendo los partidarios de la guerra justa y la esclavitud natural, quienes esgrimían, como razón de la legitimidad de estos métodos, justamente, la falta de civilidad de los indios.

Hay un episodio en la Apologética historia sumaria relatado por Las Casas muy acorde con estas ideas, es del capítulo XXI:

Yo he visto hombre en esta isla Española que estaba hidrópico, el cual se llamaba Francisco Monasterio, que tenía la barriga como una mujer preñada y la cara como unas gualdas amarillas; este, cognosciendo la virtud y sanidad de aquellas islas, porque había, según creo, andado por ellas, ó á lo ménos teníase comúnmente de la bondad dellas cierta noticia, pasóse á ellas, y en cuatro ó cinco meses volvió tan sano y tan cenceño como si mal nunca hobiera tenido, y creo de cierto, que hidrópico y después sano yo lo vide (Casas, cap. XXI [1909: 50-51]).

Podríamos llamar, a este relato intercalado, la Metamorfosis de Francisco Monasterio: de hidrópico a cenceño y sano. De "enfermo de humor aguoso [o 'seroso' según el diccionario de la RAE], que hincha todo el cuerpo" a "enjuto, con poca barriga" (Covarrubias 1611). Esta transformación es operada gracias al paisaje indiano, que determina favorablemente la salud y la buena condición física también de los españoles. Si los hombres no perturban la tierra, esta naturalmente les infunde virtud y sanidad. Las Casas, también aquí, está refutando un discurso adversario que planteaba que los indios deberían permitir que su paisaje fuera explotado y "aprovechado" por las formas de consumo occidentales. El fraile rectifica: son los españoles los que deberían dejarse influir por la naturaleza de las Indias para recuperar salud, bondad y moderación ${ }^{6}$ y seguir, así, los preceptos 
de la Ley Natural. En cambio, como se verá, los hombres que comen y beben mucho son "agrestes" o "silvestres". Estos son los términos que Las Casas utiliza para los que considera individuos "bárbaros" como, según el fraile, son los habitantes en Europa de la región que va desde Inglaterra a Polonia. ${ }^{7}$ Mientras Las Casas se sirve del modelo de Cucaña para representar el comportamiento de los españoles y el paisaje que se corresponde con ellos, emplea el de la Arcadia, moderada, utópica y feliz, para describir la armonía que concibe entre los indios y su naturaleza paradisíaca, que debe ser aprovechada al modo de vida que estos llevan con ella. Las Casas rebatirá insistentemente la concepción del Nuevo Mundo como una Cucaña, ya que estas ideas y las prácticas que se desprenden de ellas podrían transformar el paisaje fértil y ameno en desierto destemplado: "[los españoles] dejaron aquella isleta destruida y desierta, siendo el alholí del pan, por ser muy fértil (Casas, L II, c 8 [MC II: 233])". Esta cita, semejante a muchas otras, es una inserción de mano de Las Casas, probablemente posterior, que se refiere a la conquista de la isla Saona.

Ahora bien, el paisaje fértil y ameno, la Arcadia de las Antillas que se deduce de este texto, es, al momento de su escritura, una realidad ya perdida y destruida por la Conquista. La nostalgia es la consecuencia inevitable que sigue a toda descripción de un paisaje ideal; es el efecto transmitido a los lectores y causado por la evocación del recuerdo de lo que no existe más en contraste con el presente de desolación. Una cita de la Historia del fraile dominico, por ejemplo, se refiere al desenlace de la tierra de los Lucayos, la isla Guanahaní -luego de San Salvador-, primera descubierta por el Almirante: "Se despoblaron tantas y tales islas, que ya no se curaban de ir navíos a ellas, por tenellas por vacías"8 (L II, c 14 [MC II: 253]). Recordemos una cita de la Apologética referida al pasado de los Lucayos: "¿Quién contará los frutales y las naturalezas de ellos, y la suavidad y sanidad juntamente de sus frutas y la multitud numerosa, así domésticos como silvestres?" (Casas, cap. XXI [1909:51]). La obra completa de Las Casas narra la abundancia y "felicidad" de lo que se halló al comienzo y el periplo final de despoblación y "vaciamiento", que -advierte el fraile-puede repetirse en todas las conquistas.

Sin embargo, la "visión del paraíso" perdido en Las Casas es, paradójicamente, nostálgica aunque esperanzadora. Planteamos que la presencia del tópico del paraíso perdido en la Historia de las Indias y en la Apologética sumaria de Las Casas constituye un elemento disparador de la utopía como deseo y de la esperanza como efecto retórico. El pasado añorado puede convertirse en inspiración de la acción práctica. Ya Santa Arias (2000) observó en una lectura lúcida que Las Casas se hallaba marcado por la visión de la Historia de Joaquín de Fiore, en la que el pensamiento milenarista distingue tres etapas o propuestas que se corresponden con la trinidad divina: la Edad previa a Cristo, la llegada del Cristianismo y la edad venidera de salvación colectiva y milagrosa. Con esto, Arias sostiene que la Historia de las Indias, la Brevísima y el De único modo están dirigidos respectivamente por aquellos propósitos, por lo que toca, al último, la función pragmática, es decir: la agencia evangelizadora en las Indias, que persiguió recrear un paraíso nuevo, evangelizado y cristiano, en las Indias. La lectura geográfica de este artículo intenta complementar la de Arias. Consideramos que la Historia y la Apologética, como desprendimiento de la primera, también contienen un efecto retórico constitutivo dirigido a la acción utópica, impulsor de una paz diferente, pero restaurador de la naturaleza armónica que el fraile describió antes del momento de destrucción. El relato acerca de que allí muy recientemente existió un paisaje ideal en unidad e integración con sus habitantes tiene la función de generar un pensamiento esperanzador. Sobre todo, los comentarios morales o las amplificatios del fraile tienen la función de conmover e inspirar una acción práctica.

\section{Conclusión}

Se busca la restauración de esos ideales de perfección y de racionalidad para la convivencia de los individuos con su ambiente. Consideramos, de esta manera, que la Historia de Las Casas es utópica porque su situación de enunciación "híbrida" contiene ambas convicciones: la de un paraíso perdido y la de una utopía posible en el futuro. El primero abre la posibilidad a la segunda. Para que se den las condiciones de esta restauración utópica originaria del Nuevo Mundo, los futuros actores de la Conquista deben "saber la costumbre" noble y fértil de la naturaleza e integrarse a ella. También los cronistas deben hablar "con la verdad" y desmentir lo que otros "falsos" afirman. Las Antillas 
como "alholî" o "hacienda" fértil en su justa medida solo se recuperarán con las acciones de hombres moderados, que "saben ya la costumbre de la tierra" y "comienzan a gustar de la nobleza della y fertilidad" (L I, c 162 [MC II:111]). El futuro, una vez abandonado el "pecado de la codicia" en los españoles, devolverá "con ventaja" la fertilidad que ese jardín tenía en tiempos pasados si se eligen, para habitar las Indias, a pastores o a agricultores sencillos que no corrompan la tierra.

\section{Referencias Citadas}

Aliata, F. y Silvestri, A.

2001 El paisaje como cifra de armonía. Nueva Visión, Buenos Aires.

Arias, $\mathrm{S}$.

2000 Retórica, Historia y Polémica. Bartolomé de las Casas y la tradición intelectual renacentista. Oxford- University Press of America, New York.

Baczko, B.

1991 Los imaginarios sociales, Memorias y esperanzas colectivas. Nueva Visión, Buenos Aires.

Bloch, E.

1979 El principio esperanza. Aguilar, Madrid.

Casas, B. de las

1909 [siglo XVI]. Apologética Historia de las Indias. Edición preparada por Serrano y Sanz. Bailly, Bailliére e Hijos, Madrid.

1981 [siglo XVI]. Historia de las Indias. ed. de A. Millares Carlo y estudio preliminar de Lewis Hanke. FCE, México. [Las abreviaturas en el cuerpo del texto corresponden a "Libro" ("L"), "capítulo" ("c") y edición de "Millares Carlo" ("MC")].

Colón, C.

2012. Diario, cartas y relaciones. Antología esencial. Edición, prólogo y notas a cargo de Valeria Añón y Vanina Teglia, Corregidor, Buenos Aires.

Comparato, V.

1995 Utopía, Léxico de política. Ediciones Nueva Visión, Buenos Aires.

Curtius, E. R.

1955 Literatura europea y Edad Media latina. FCE, México.

Davis, J. C.

1985 Utopía y la sociedad ideal. FCE, México.

Frankl, V.

1963 Imperio particular e imperio universal en las cartas de relación de Hernán Cortés. Revista Cuadernos Hispanoamericanos, 165:443-482, Aecid, Madrid.
Frye, N.

2001 El gran código: una lectura mitológica y literaria de la Biblia. Gedisa, Barcelona.

Gerbi, A.

1960 La disputa del Nuevo Mundo. FCE, México.

Hamón, $\mathrm{P}$

1991 Introducción al análisis de lo descriptivo. Edicial, Buenos Aires.

Lavallé, B.

1993 Las promesas ambiguas. Ensayos sobre el criollismo colonial en los Andes. Instituto Riva-Agüero de la Pontificia Universidad Católica del Perú, Lima.

Levin, $\mathrm{H}$.

1972 The Myth of Golden Age in the Rennaissance. Oxford University Press, Nueva York.

Manuel, F. y Manuel, F.

1984 El pensamiento utópico en el mundo occidental. Taurus, Madrid.

Mártir de Anglería, $\mathrm{P}$.

2004 De Orbe Novo. Estudio preliminar, traducción y notas de Cro, Stelio, Alción Editoria, Córdoba-Argentina.

Oviedo, G. Fernández de

1959 [siglo XVI]. Historia General y Natural de las Indias. ed. de Juan Pérez de Tudela, Atlas, Biblioteca de Autores Españoles, Madrid.

Pagden, A.

1988 La caída del hombre natural. Alianza Editorial. Versión española de Belén Urrutia Domínguez, Madrid.

Solodkow, D.

2014 Etnógrafos coloniales. Alteridad y escritura en la Conquista de América (siglo XVI). Iberoamericana-Vervuert, Madrid.

Zumthor, P.

1993 La medida del mundo. Cátedra, Madrid.

\section{Notas}

1 De hecho, su título completo es Apologética historia sumaria: cuanto a las cualidades, disposición, descripción, cielo y suelo destas tierras, y condiciones naturales, policías, repúblicas, maneras de vivir y costumbres de las gentes destas Indias occidentales y meridionales, cuyo imperio soberano pertenece a los Reyes de Castilla.

2 "La tierra misma, libremente, sin que el azadón/ la tocase ni el arado la hiriera, lo daba todo por sí misma,/y, contentos con el alimento producido sin exigirlo nadie,/ recogían los frutos (...)" [Ovidio, 1991, vv:101-104].

3 Véase Lavallé, quien aclara que, por ejemplo, Santo Tomás: "en su Summa contra gentiles había dado razones climáticas a ciertas formas de esclavitud" [1993: 50]. Aristóteles explicaba que, ya que el cuerpo está controlado por humores, los Scitas, que vivían en climas fríos, tenían humores "calientes" que los hacían impetuosos y "muy parecidos a los borrachos" [Problemata, 910 a 30. (citado en Pagden, 1988:192)].

4 Juan López de Velasco, Geografía y descripción universal de las Indias, Madrid, BAE, CCXLVIII, 1971, p. 27. [citado en Lavallé, 1993:54]

$5 \quad$ Para Northrop Frye [2001: 74]: "La pastoral, aunque carece de importancia política, sin embargo, mantiene abierta la sugerencia de que el estado de naturaleza y el estado 
de sociedad eran estados diferentes, quizá opuestos. La pastoral se aliaba con el espíritu satírico, que, como en el Elogio de la locura de Erasmo y en la Vanidad de las artes y de las ciencias, de Cornelio Agripa, ponía en cuestión globalmente el valor de la civilización". Véase también Comparato [1995], Zumthor [1993] y Baczko [1991]. Esta "visión" de la pastoral opuesta al estado de sociedad sí funciona plenamente en las representaciones sobre las Indias de Pedro Mártir de Anglería. Por ejemplo: "Pero yo pienso que nuestros indios de la Hispaniola son más felices que aquellos, con que acepten la religión cristiana, porque desnudos, sin pesas ni medidas, sin el mortífero dinero, viviendo en la edad dorada, sin leyes ni jueces engañosos, sin libros, contentos del estado natural, pasan la vida sin preocuparse para nada del futuro" [2004: 133].

6 El Diccionario de Autoridades [1739] da el siguiente ejemplo curioso, extraído de una traducción de Tácito, para la entrada "temperatíssimo": "Entre las otras virtudes que tuvo, fue temperatíssimo en el comer, y beber, y en todo lo demás".

7 Véase la Apologética de Las Casas, cap. XXIX (1909:72).

8 El término "vacías" en consonancia con la connaturalidad entre paisaje y habitantes de las visiones lascasianas alude tanto a tierras asoladas como a comunidades despobladas. 
